\title{
UV Index and Total Ozone Column Climatology of Nepal Himalaya Using TOMS and OMI Data
}

\author{
R.R. Sharma ${ }^{1}$, B. Kjeldstad ${ }^{2}$, and P. J. Espy ${ }^{2}$ \\ ${ }^{1}$ Department of Hydrology and Meteorology, Kathmandu, Nepal \\ ${ }^{2}$ Department of Physics, Norwegian University of Science and Technology, Trondheim, Norway.
}

\begin{abstract}
Ultraviolet index (UVI) and Total Ozone Column (TOC) climatology of six stations of Nepal Himalaya using ground measurement, and OMI / TOMS satellite data is presented. The positive bias found in the OMI UV index from previous study is corrected empirically using a ratio factor using the clear sky coincident data of OMI and ground measurement from NILU UV multi-band filter radiometer (MBFR). UV index $>3$ in the winter months (e.g. December) and more than 9 during the summer months (May-August) are common in most of the stations. High altitude stations even have more extreme values (>11) during the summer months. Under some meteorological conditions, UV index often found more than 16 at the high altitude station (latitude 28, altitude $2850 m$ ) during a clear sky day in the monsoon season. Diurnal and altitudinal variability is also highlighted. Monthly average TOC climatology from November 1978 to March 2012 using TOMS (Nimbus 7, Meteor3 and Earth Probe) and OMI is also presented. The ozone column data follows the annual cycle, minimum in November/December and maximum in April/May. In addition, slight negative trend of TOC is found in the data from 1978 to 2012.
\end{abstract}

Keywords: UV index, Total Ozone Column, Nepal Himalayas, TOMS/OMI data, Climatology, NILU UV

\section{INTRODUCTION}

UV index climatology deals the seasonal variability, long-term average (normal), and its trends and provides the valuable information to the policy makers and the scientists concerned with UV radiation and its effect on human health. The study of total ozone column (TOC) is particularly important to monitor the fate of ozone layer after the famous ozone hole episode and the effectiveness of Montreal protocol and its amendments of controlling mechanism of Ozone Depletion Substances (ODS) (WMO, 2010). Although, stratospheric ozone and ground level erythemal ultraviolet radiation has, in general, an out-phase relationship but recovering stratospheric ozone does not necessarily bring backs the ground level UV radiation to its previous stage due to various interacting processes (Watanabe et al., 2011). However, other scientists (Bais et al., 2011) believed that the stratospheric ozone recovery by 2090's as compared to 1980's level would decrease the surface erythemal UV radiation by as much as $12 \%$ at high latitude, nearly $3 \%$ at mid latitude but marginally $1 \%$ higher in the tropics. In the high altitude tropical region, for example, at the Himalayas, UV index is believed to be very high during the summer. 
For cloud free, snow free and aerosol free atmosphere, satellite UV radiation reaching the earth surface can be estimated with reasonable accuracy in a Rayleigh-scattering atmosphere using total ozone and surface reflectivity (Krotkov et al., 2001). In OMI UV product, cloud is estimated from the Lambert Equivalent Reflectivity (LER) derived from the OMI measured radiance $\left(I_{360}\right)$ near $360 \mathrm{~nm}$ (Krotkov, 2002, Eck et al., 1995). The ground instrument (NILU UV) uses Cloud Transmission Factor (CLT), the ratio of measured to clear sky surface irradiance with no aerosol and zero surface albedo, to estimate the surface UV radiation.

Four UV monitoring stations equipped with NILU Moderate Band Filter Radiometer (MBFR) have been established at different altitudes of Nepal Himalaya in recent years (2008-2010) under a Solar radiation and Aerosol in Himalayan Region (SAHR) project funded by the Development, Research and Education (NUFU) Program of Norway (20072012). These data are particularly important to validate the similar data obtained from the satellite which has relatively longer acquisition period and global coverage. Sharma et al., (2011) compared the UV index and TOC data obtained from these ground measurement with the Ozone Monitoring Instrument (OMI) and found the positive bias on OMI as much as $34.5 \pm 24.0 \%$ to $47.9 \pm 17.4 \%$ for cloud free condition and much higher on cloudy condition using the intermittent data. The study also found that the bias of total ozone column under cloud free condition vary from $-2.17 \pm 3.52 \%$ to $2.97 \pm 3.92 \%$. The correlation coefficients were more than 0.85 for all the stations. The mean ozone column obtained from ground instrument varies from 255.1 to 285.5 (DU) and OMI ozone column varies from 262.7 to 279.0 (DU).
High elevation areas receive more UV radiation due to shorter path length and low atmospheric attenuation, less influence of boundary layer aerosol due to less concentration, and more sky visibility and less influence of cluttering obstacles like mountains and man-made features. Other things remains the same, altitude variation may affect the erythemal UV radiation by as much as $5-23 \% / \mathrm{km}$ (Pfeifer et al., 2006) depending upon the different topography. In Tibet, altitude effect of UVI is found $7-8 \% / \mathrm{km}$ (Dahlback et al., 2007).

In Nepal people permanently lives close to 4000 $\mathrm{m}$ a.s.1. and seasonal migration for business and trade, trekking and mountaineering, makes people's movement at much higher altitude where the level of erythemal UV radiation and its impact on the human health is unknown. The main objective of the study is to present the UV index climatology of six sites from Nepal Himalayas using Aura OMI satellite product from October 2004 to March 2012. The satellite data is first empirically corrected using the ground data. Furthermore, total ozone column (TOC) climatology using TOMS (Nimbus 7, Meteor 3 and Earth Probe) and OMI is also studied using the data from November 1978 to March 2012. The paper also discusses the diurnal variability of UV index using ground measurements.

After the first introductory section, section 2 describes the ground and satellite based data and instrumentation. Section 3 describes the methodology and an approach for empirical correction of OMI UVI using ground data for clear sky condition. Section 4 presents the results of diurnal variability, UVI and ozone climatology with discussion. Section 5 concludes the paper. 


\section{DATA AND SITE DESCRIPTIONS}

2.1 Description of Ground Station and Instrumentation

Four UV monitoring stations were established in Nepal between the periods of October 2008 to October 2009. Solar Radiation and Aerosol in Himalayan Region (SAHR) project under the Institute of Engineering of Pulchowk Campus of Tribhuvan University has been taking the responsibility for operating and maintaining the stations.

The stations cover elevation range of $70 \mathrm{~m}$ to $2850 \mathrm{~m}$ in the southern slope of Himalayan region within the latitude range from $26.45^{\circ}$ to $27.72^{\circ}$ and longitude range from $83.32^{\circ}$ to $87.27^{\circ}$. The stations cover different geographical and environmental setting. Nepal receives about $80 \%$ rain during the monsoon season (June to September) from southeast monsoon originating from the Bay of Bengal. Pollutants are usually at low level in this period and sky often covered by clouds. During the winter (December to February), rain mainly occurs due to westerly disturbance, and its effect gradually slow down from west to east. These four stations have also unique local setting. The lowermost station, Biratnagar, lies in the southern flat land. It is a moderate size urban city close to Indian border. Temperature is mild and hot during the year and may reach above $40^{\circ} \mathrm{C}$ in summer. Pokhara is a valley of Middle Mountain range with altitude of $850 \mathrm{~m}$ a.s.l. It receives highest rainfall (about $4000 \mathrm{~mm}$ ) in a year. Frequency of rainy days is also highest in the station. Pollutants usually settled down by afternoon rain. Kathmandu lies in the capital valley of middle mountain range of elevation $1350 \mathrm{~m}$ with more than 3 million populations. Bowl shaped valley and formation of inversion layer often trap the pollution at the bottom of the atmosphere. The sky of the valley is often hazy throughout the winter unless a rain settles the dust and aerosol. Lukla station lies in the southern slope of High Mountain range nearby Mountain Everest at an elevation of $2850 \mathrm{~m}$. The atmosphere is relatively clean as compared to other stations. In addition, two OMI overpass data are also available for Dhangadhi $\left(28.0^{\circ} \mathrm{N}, 80.55^{\circ} \mathrm{E}\right.$, altitude 187 $\mathrm{m}$, low land and flat) and Simikot $\left(29.97^{\circ} \mathrm{N}\right.$, $81.82^{\circ} \mathrm{E}$, altitude $2800 \mathrm{~m}$, a mountainous site).

All four ground stations are equipped with multiband filter radiometer (MBFR) manufactured by Norwegian Institute for Air Research (NILU). The NILU-UV instrument has five channels in UV region with centre wavelength at 302 , $312,320,340$ and $380 \mathrm{~nm}$ and bandwidths of approximately $10 \mathrm{~nm}$ at full width half maximum (FWHM). It has also a sixth channel which measures photosynthetic active radiation (PAR) in the wavelength range 400-700 nm. Data taken from multi band filter radiometer (MBFR) combined with radiative transfer model provide reliable data on biologically effective UV dose rates (UV Index), total ozone column, effective cloud optical depth or cloud transmission, and high wavelength resolution UV spectrum (Høiskar et al., 2003). Dahlback (1996) has given all the details to estimate these parameters and found good agreement with the high-resolution spectroradiometer. The NILUUV instrument is temperature stabilized at $50^{\circ} \mathrm{C}$. Four NILU-UV instruments are installed at the four stations whereas the fifth instrument is kept as a reference instrument for mobile calibration. To track the sensitivity of the instrument, relative calibration is performed every week. The reference instrument was participated to the second Quality Assurance of Spectral Solar UV measurements in Europe (QASUME) audit in June 2010, Oslo, and the new calibration level is transferred (Grobner, 2010). 


\subsection{Aura-OMI UV index}

Aura is a multinational satellite of collective effort from USA, the Netherlands and Finland and flown in July 2004. Aura has four instruments one of them is Ozone Monitoring Instrument (OMI). OMI provides information of various atmospheric variables such as ozone, aerosols, clouds, surface UV irradiance, and other trace gases (Kazadzis et al., 2009). OMI is a wide swath, sun synchronous, nadir viewing, near-UV and visible spectrometer that measures solar UV and visible radiation in the range of 270 to $500 \mathrm{~nm}$ (Tanskanen et al., 2007). It covers swath of $2600 \mathrm{~km}$ with spatial resolution of $13 \times 24 \mathrm{~km}$ at nadir. The orbital period of Aura satellite is about 98 minute and equatorial crossing time is 13:42 hour local time. It scans the earth surface during ascending mode. One of the advantages of the satellite data is the global coverage and all weather capability.

Ozone Monitoring Instrument (OMI) utilizes ozone and reflectivity data measured by the satellite itself and other sources of information like surface albedo, temperature profile, and ozone profile to estimate the surface UV irradiance by using radiative transfer model. It first estimates the ground UV irradiance assuming clear sky condition and later a cloud modification factor is used to estimate the ground UV under cloudy condition. If the ground surface is also covered by snow, a surface albedo is also used in the model. Cloud modification factors are derived from the reflectivity measurement. Absorbing aerosol is not accounted in the present version of OMI UV index which causes the systematic bias in the OMI data. The details can be found in the OMI ATBD documents (Levelt et al., 2002).

\section{METHODS AND EMPIRICAL CORRECTION OF OMI UVI}

In UV range, surface albedo is usually around 0.02 to 0.07 in most of the land surfaces (Eck et al., 1995). Dry sands has higher albedo but less than 0.1 . Snow has usually very high albedo, up to $90 \%$ for fresh snow. Therefore, choosing a threshold of 0.1 is reasonably a good decision to separate the snowy surface and non-snowy surface (Tanskanen et al., 2007). The stations studied here have snow free surfaces most of the time throughout a year. Only high altitude stations may have surface albedo $>0.1$ due to snowfall in the winter season (December to February).

In this study, coincide measurements between the satellite and ground at satellite overpass time are used. These data are extracted from the databases of both the satellite and ground where time matching is the nearest minute. A plot of surface albedo, used by satellite UV retrieval algorithm, and the date of the coinciding measurements show that there are no data above 0.1 in the winter season (Figure 1). However, in the monsoon season (June to September), we found that significant numbers of data pairs have surface albedo $>0.1$. The figure reveals that the climatology value used by OMI to retrieve the UV index is unrealistically higher for the monsoon season which may be due to the confusion with low clouds or fogs.

Cloudy days and cloud free days are separated from the coincident measurement data using the Lambertian Equivalent Reflectivity (LER) at $360 \mathrm{~nm}$. Therefore, the overpass data are categorized into cloud-free cases where LER is $<0.10$ and cloudy cases where LER is more than or equal to 0.10 (Kalliskota et al., 2000; Anton et al., 2010). The relationship between Lambert equivalent Reflectivity, (LER) and 


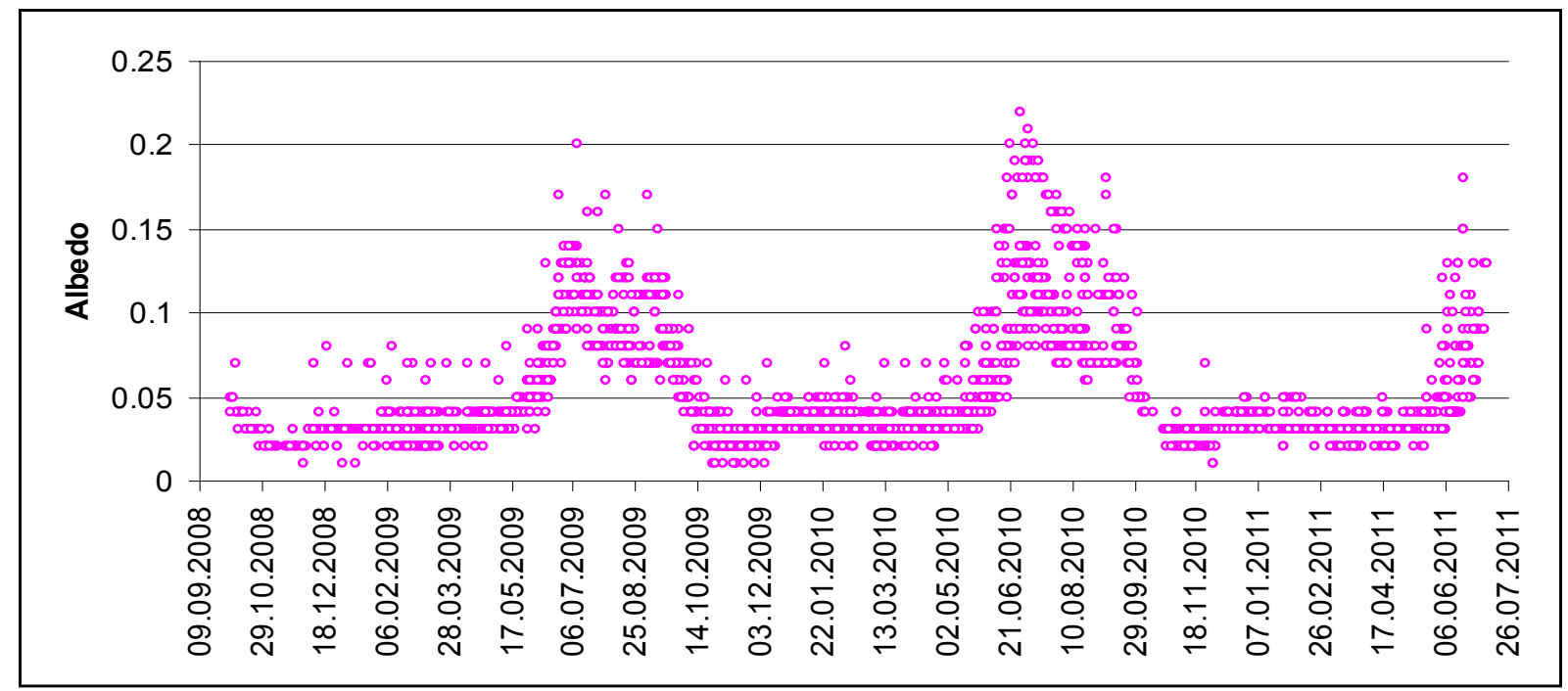

Figure 1: Time series plot of OMI surface albedo of coincidence measurement at satellite overpass time.

Cloud Optical Depth (CLDOPT) of OMI for coincidence overpass data of satellite and ground of Nepal shows the contrasting characteristics (Figure 2). Zero cloud optical depth for large LER values up to 0.8 is often observed which may be due to the poor response of OMI satellite in such high altitude region like the Himalayas. In fact, OMI considers cloud free sky above a certain height $(2 \mathrm{~km})$.

Ground data of Nepal also includes Cloud Transmission Factor (CLT), which is a ratio of measured irradiance to calculated clear-sky irradiance with zero aerosols and zero surface albedo for a particular solar zenith angle (Høiskar et al., 2003). CLT is calculated on that spectral channel where ozone absorption is minimal. It may be larger than $100 \%$ when instrument observed direct sun as well as diffuse radiation from cloud scattering. The comparison study between the OMI and the ground UVI shows that the percentage bias $[($ omi-gd $) / g d \times 100]$, where omi is the OMI UV Index and $g d$ is the ground measured UV index, which increases with decreasing the cloud transmission factor (Sharma et al., 2011).

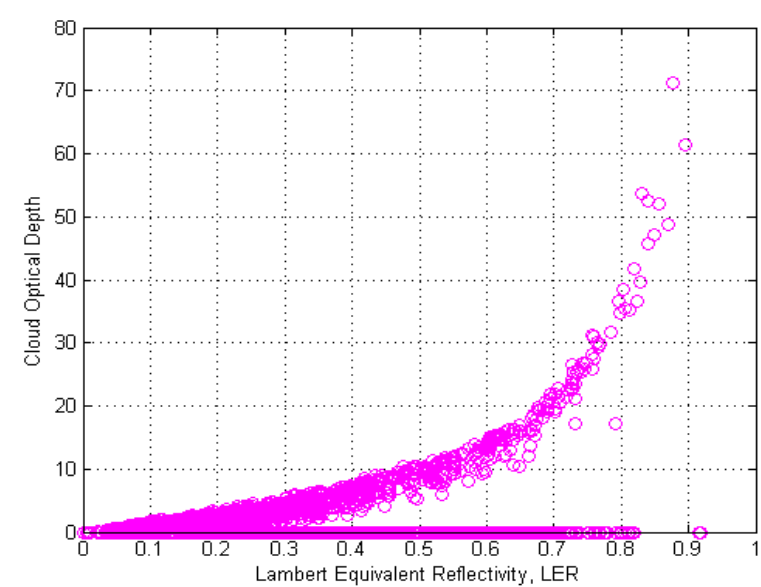

Figure 2: Plots of Lambert Equivalent Reflectivity (LER), and Cloud Optical Depth (CLDOPT) of OMI for coincidence overpass data from Nepal.

In this study, the bias observed in the OMI overpass UVI is corrected using an empirical ratio factor. First, the cloud-free and snow-free pairs of OMI and ground data are extracted using the proxies, Lambert equivalent reflectivity $(<0.1)$ and surface albedo $(<0.1)$ with the thresholds. After that, a threshold of cloud transmission factor is selected by looking the oval shape ground data for clear sky condition. The threshold varies for different stations; however, a common threshold, 70\%, works well 
to all the station. Since OMI overpass data also provides clear sky UVI at local noon, we use this product for our climatology study. The time series plot between the OMI and the ground for simultaneous measurement for clear sky conditions is shown in Figure 3. Since OMI's equatorial crossing time is close to $13: 45$ hours local time, the coincidence data often missed the local-noon maximum. Total 443 pairs are found satisfying the cloud-free and snow-free condition. The mean of the OMI and ground
(GD) are 6.8 and 4.3 and standard deviation of 2.3 and 1.6 respectively. We then divide the ground mean data by the OMI mean and get a factor $0.633 \pm 0.122$ which is used to correct the OMI data for clear sky condition at local noon.

\section{RESULTS AND DISCUSSIONS}

\subsection{Diurnal Pattern of the UV Index}

Diurnal pattern of the UV index obtained from NILU UV multi-band filter radiometer (MBFR
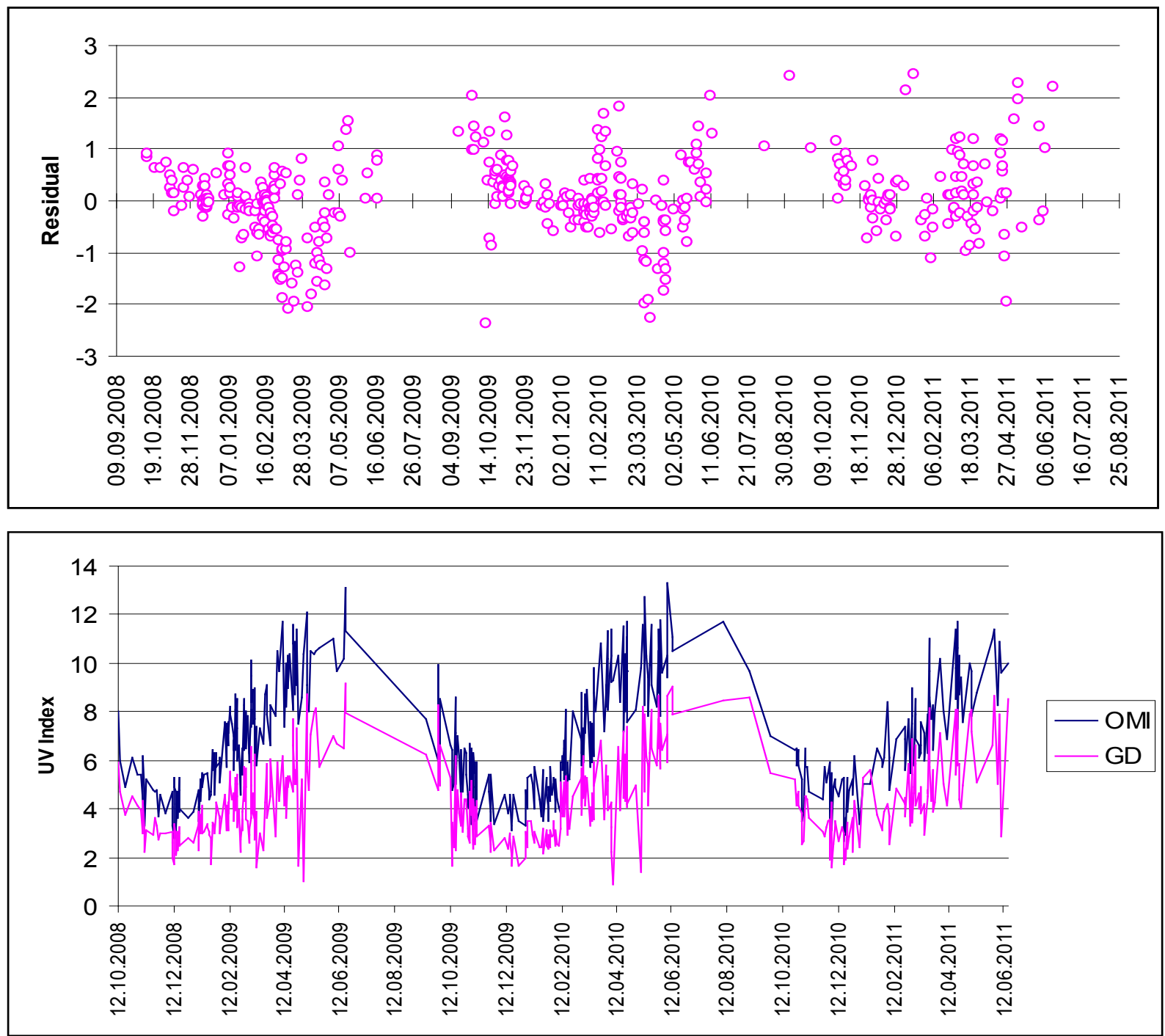

Figure 3: Coincidence overpass data of OMI and ground for cloud free condition. Cloud free data in the monsoon period is distinct (top) and the distribution of residual after applying an empirical correction factor on OMI data for clear sky condition (bottom). 

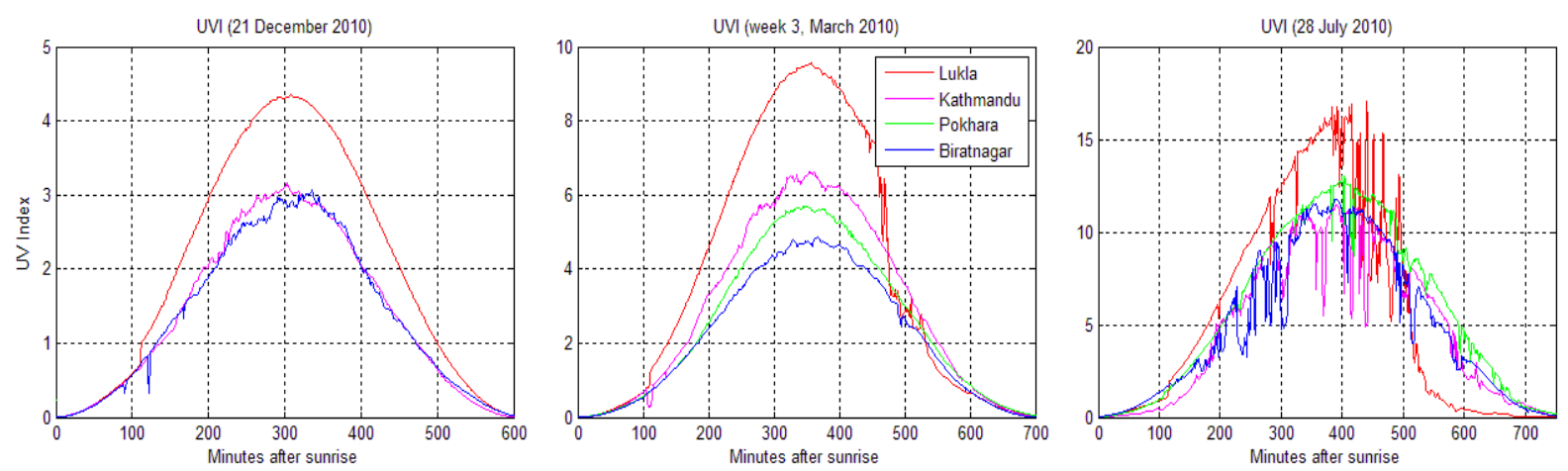

Figure 4: Diurnal pattern of ground measured UV index for 21 December 2010 (left), 21 March 2010 (middle) and 28 July 2010 for Lukla (red), Kathmandu (magenta), Pokhara (green), and Biratnagar (blue).

with one-minute sampling rate for different stations and for typical day is given in Figure 4. The UV index of the lowest altitude stations (Biratnagar, $70 \mathrm{~m}$ ) reaches close to three at the local noon in December 21 whereas in Lukla $(2850 \mathrm{~m})$ the UVI reaches close to 4.5 on the same day. One can expect more UVI in Kathmandu $(1350 \mathrm{~m})$ on that day because of higher elevation compared to Biratnagar (blue line). However, local pollution and stagnant air limits the UV radiation reaching to the ground surface. In Kathmandu valley, air pollution is usually high in the winter period (DecemberFebruary). Occasional rains due to westerly disturbance wash out the local pollution and the UVI level becomes stronger.

In the vernal equinox, for example, March 21, the UVI increases in all the stations as compared to winter solstice. In Lukla, UVI reaches above nine and lowest altitude station (Biratnagar) receives UVI close to 4.5. All the stations in the plot have cloud free sky at least first half of the day. Small cripples in the UVI curve is due to the movement thin cirrus cloud or aerosol effect over the stations. The middle plot (Fig. 4) also clearly depicts the altitudinal effect of UVI. We have found different rates $7.5 \%-35 \% / \mathrm{km}$ for different seasons and different condition (hazy versus clean).

UVI reaches very high to extreme level at the clear sky days of the rainy seasons. Relatively lower aerosol load in the season permits high UV radiation to the ground. Of course, cloud controls much of the UV radiation reaching the ground. The right plot in the Fig. 4 shows that in all stations UVI level is very high to extreme level. The UVI level at Lukla crosses 16 in a typical day of 28 July 2010.

According to the WHO (2002), UV index more than 3 needs some sort of protection to be used. UV index 3 to 5 categorized as moderate, 6 to 7 as high, 8 to 10 very high, and more than 11 as extreme. Since, the sites are from the northern hemisphere and the above days are from the near vernal equinox, the maximum UV index values for clear sky days often reached $>3$ throughout the year in all the stations. Theoretical minimum value of UV index for clear sky days can be expected during the winter solstice. The UV index value during the winter solstice is also beyond or close to three (left plot). Similarly, theoretical maximum UV index value can be expected in summer solstice; however, monsoon cloud can compensate it. 


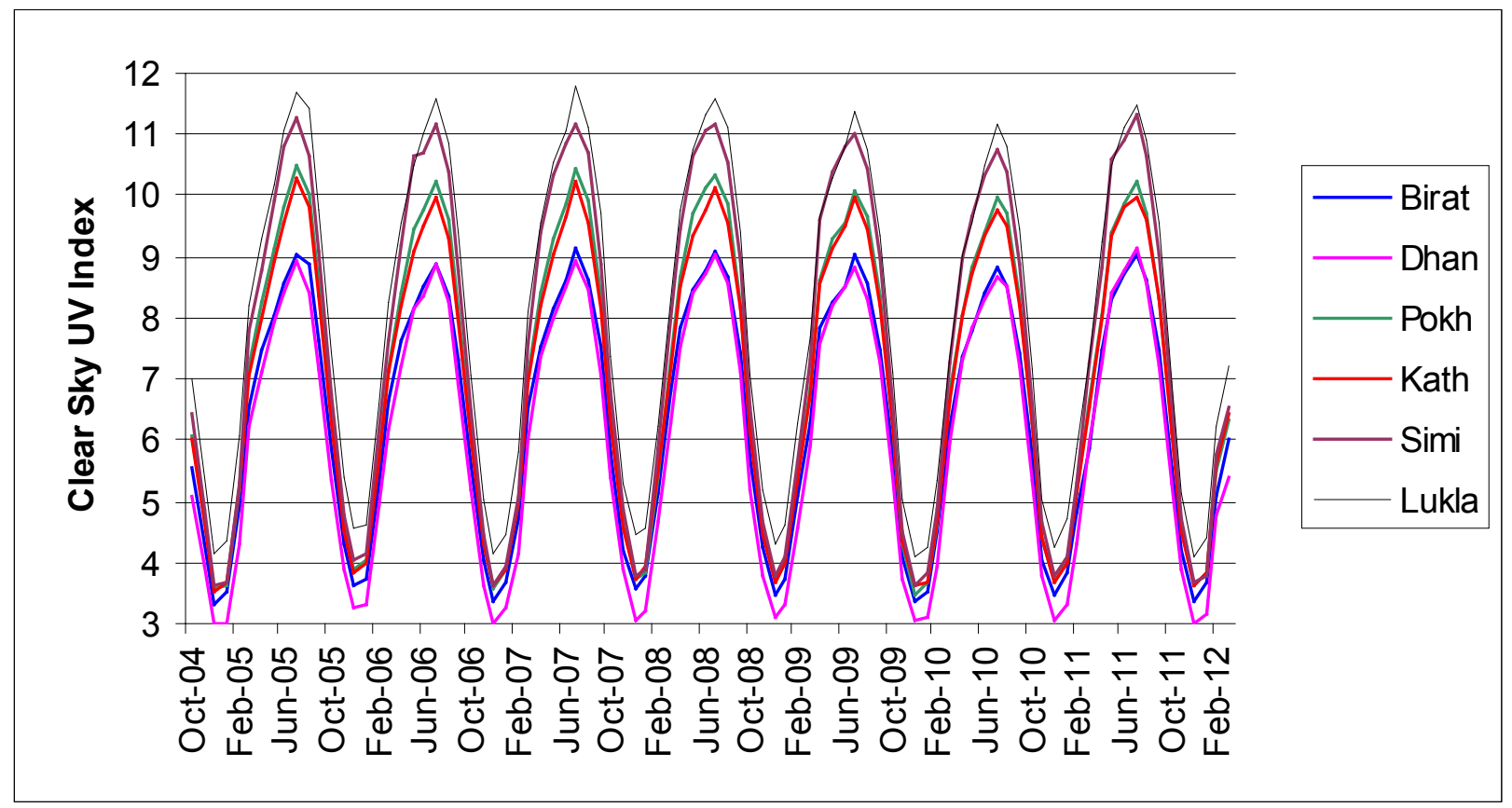

Fig. 5: Time series of monthly average UVI for all six sites of Nepal Himalayas from October 2004 to March 2012 using AURAOMI satellite data, after applying a correction (The short names of the stations are as follows: Birat = Biratnagar, Dhan = Dhangadhi, Pokh = Pokhara, Kath = Kathmandu, Simi = Simikot, Lukla = Lukla).

One point to note that the ground stations only cover a limited elevation range of Nepal land masses. Since the country's highest land mass reached up to the top of the world, Mt. Everest, $8848 \mathrm{~m}$, a much more UV index can be expected in the further elevated zones. Since OMI covers all the reason of the globe, it is worthwhile to use the OMI data to find UV level at those regions.

\subsection{UV index climatology}

A time series plot of monthly average clear sky UVI at local noon using OMI overpass data after applying a correction factor is shown in Figure 5. The figure follows an annual cycle, minimum in December and maximum in July. During the winter period, UVI reaches as low as 3-4 and during the summer months UVI reaches up to 9-11.5. Altitudinal variation is also distinct in the plot. Biratnagar and Dhangadhi are the low altitude stations (below $200 \mathrm{~m}$ ), Simikot and Lukla are the high altitude stations (2800$3000 \mathrm{~m}$ ) whereas Pokhara and Kathmandu are in the middle altitude stations (850-1350). The monthly average UVI covering October 2004 to March 2012 and its variation with $\pm 1 \sigma$ (one standard deviation) for all six locations is also shown in Figure 5 and Table 1. In low altitude stations, the UVI increases from January, reaches to its maximum level in July, and decreases again up to December. The typical UVI values are 3 to 9. In middle altitude stations (Pokhara and Kathmandu), the UVI fluctuates between 4 to 10 and for the high altitude stations the UVI ranges 4 to 11 throughout a year. The monthly average UV index climatology for clear sky days at local noon for all six locations using OMI overpass data is also shown in Figure 6 with one standard deviation error bar. 
Table 1: Monthly mean and standard deviation of clear sky noon time UV index for six locations of Nepal Himalayas using OMI daily Overpass data.

\begin{tabular}{llllllllllllll}
\hline Location & Para & Jan & Feb & Mar & Apr & May & Jun & Jul & Aug & Sep & Oct & Nov & Dec \\
& $\mu$ & 3.7 & 5.0 & 6.4 & 7.6 & 8.2 & 8.6 & 9.0 & 8.6 & 7.5 & 5.7 & 4.2 & 3.4 \\
Biratnagar & $\sigma$ & 0.32 & 0.55 & 0.54 & 0.45 & 0.40 & 0.36 & 0.32 & 0.37 & 0.46 & 0.58 & 0.35 & 0.23 \\
& $\mathrm{n}$ & 262 & 234 & 248 & 228 & 238 & 227 & 236 & 232 & 218 & 261 & 240 & 261 \\
& $\mu$ & 3.2 & 4.5 & 6.1 & 7.3 & 8.1 & 8.5 & 8.9 & 8.4 & 7.1 & 5.3 & 3.8 & 3.1 \\
Dhangadhi & $\sigma$ & 0.35 & 0.60 & 0.63 & 0.51 & 0.40 & 0.38 & 0.36 & 0.43 & 0.55 & 0.60 & 0.38 & 0.25 \\
& $\mathrm{n}$ & 262 & 239 & 247 & 229 & 236 & 227 & 236 & 231 & 217 & 259 & 237 & 260 \\
& $\mu$ & 3.9 & 5.2 & 7.0 & 8.4 & 9.3 & 9.8 & 10.3 & 9.8 & 8.3 & 6.2 & 4.5 & 3.7 \\
Pokhara & $\sigma$ & 0.44 & 0.68 & 0.75 & 0.69 & 0.61 & 0.58 & 0.55 & 0.59 & 0.64 & 0.73 & 0.49 & 0.31 \\
& $\mathrm{n}$ & 265 & 237 & 246 & 230 & 238 & 228 & 236 & 231 & 219 & 258 & 241 & 260 \\
& $\mu$ & 3.9 & 5.3 & 6.9 & 8.2 & 9.1 & 9.6 & 10.1 & 9.5 & 8.2 & 6.2 & 4.5 & 3.7 \\
Kathmandu & $\sigma$ & 0.42 & 0.69 & 0.71 & 0.65 & 0.61 & 0.63 & 0.62 & 0.62 & 0.67 & 0.72 & 0.45 & 0.31 \\
& $\mathrm{n}$ & 259 & 236 & 247 & 227 & 239 & 230 & 239 & 231 & 218 & 257 & 237 & 258 \\
& $\mu$ & 3.9 & 5.5 & 7.5 & 9.2 & 10.3 & 10.8 & 11.1 & 10.5 & 8.9 & 6.6 & 4.7 & 3.8 \\
Simikot & $\sigma$ & 0.48 & 0.80 & 0.95 & 0.80 & 0.59 & 0.41 & 0.40 & 0.49 & 0.62 & 0.76 & 0.48 & 0.36 \\
& $\mathrm{n}$ & 260 & 239 & 252 & 231 & 236 & 227 & 236 & 235 & 222 & 263 & 239 & 259 \\
& $\mu$ & 4.5 & 6.1 & 7.9 & 9.5 & 10.3 & 11.0 & 11.5 & 11.0 & 9.5 & 7.1 & 5.2 & 4.3 \\
Lukla & $\sigma$ & 0.47 & 0.75 & 0.81 & 0.74 & 0.69 & 0.66 & 0.62 & 0.64 & 0.69 & 0.81 & 0.54 & 0.36 \\
& $\mathrm{n}$ & 262 & 235 & 249 & 229 & 241 & 230 & 240 & 235 & 221 & 261 & 240 & 260 \\
\hline
\end{tabular}
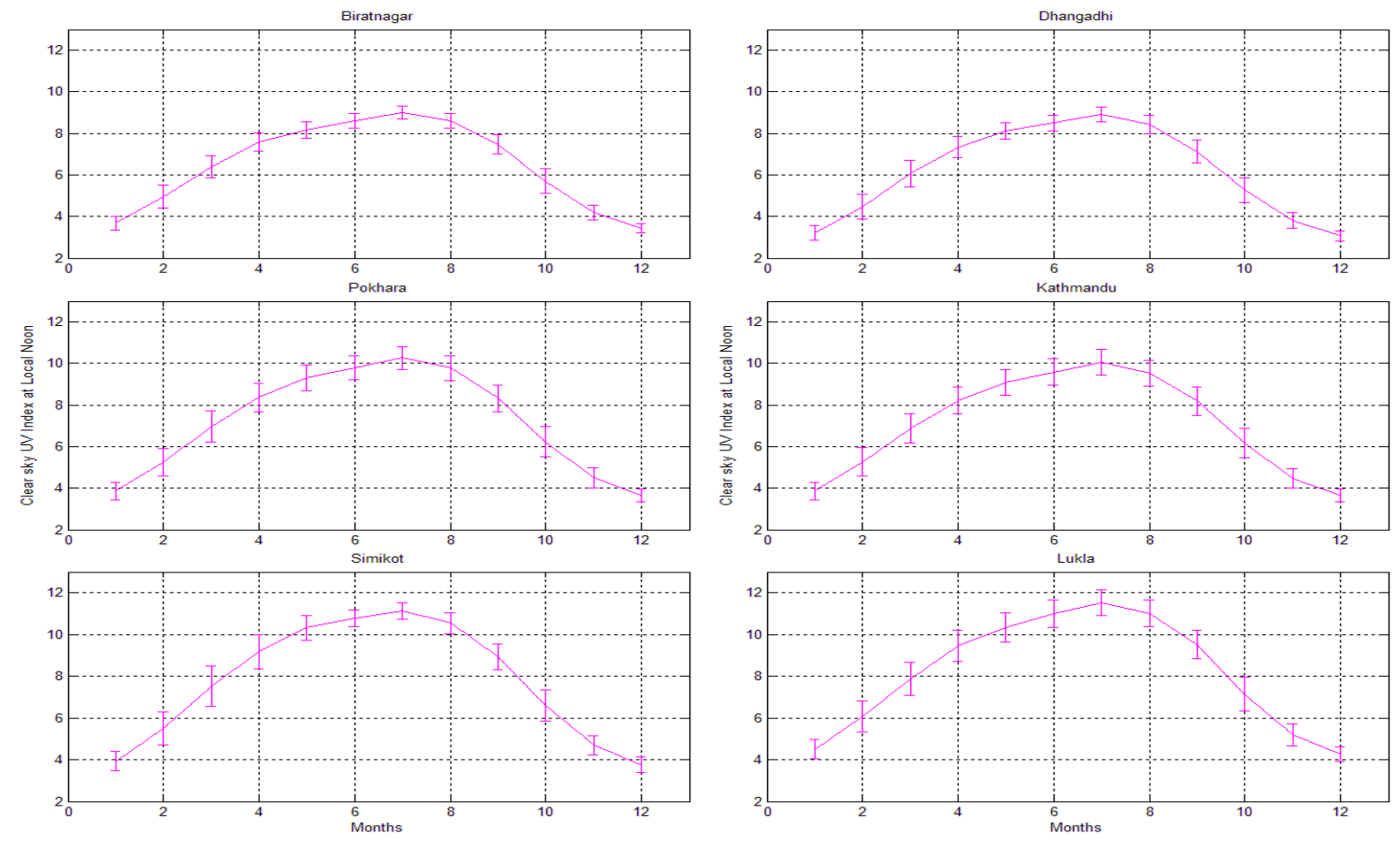

Figure 6: Monthly average UV index climatology for clear sky days at local noon for all six location of Nepal using OMI overpass data. Error bar shows $\pm 1 \sigma$ of the standard deviation. 


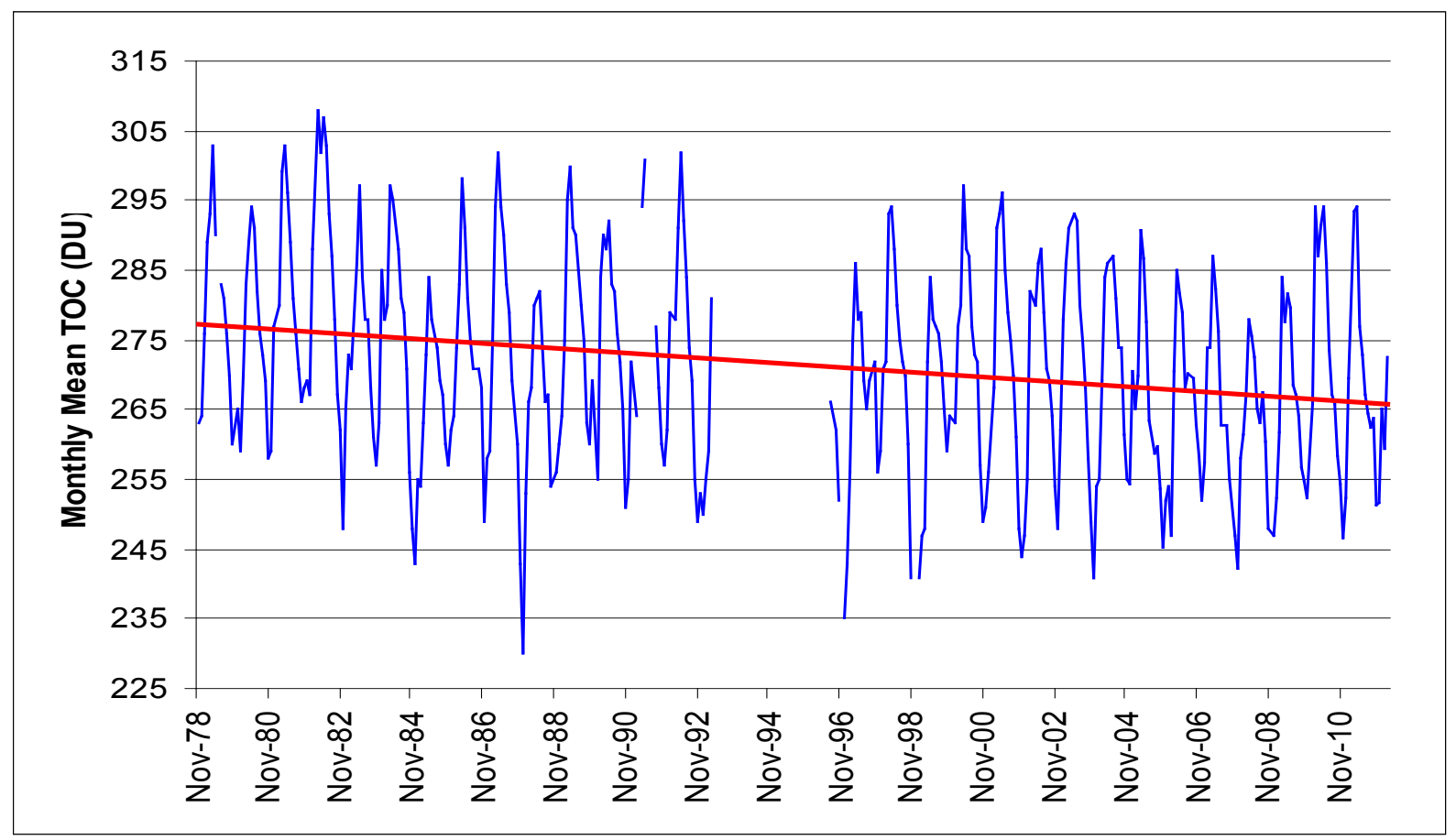

Figure 7: Climatology of total ozone column for Kathmandu, Nepal, from Oct. 2004 to Mar. 2012 using TOMS and AURA-OMI satellite data with a trend in red line.

\subsection{Columnar Ozone Climatology}

Monthly mean columnar ozone obtained from TOMS/OMI from November 1978 to March 2012 is shown in Figure 7. TOMS ozone before 2005 is taken from the Nimbus 7, Meteor 3 and Earth Probe satellites. The OMI overpass data also provides columnar ozone using TOMS like algorithm. The OMTO3_O3 product of OMI overpass is an average value of $13 \times 24 \mathrm{~km}$ at nadir and the pixels in a different position of the swath covers a larger area than the nadir. Columnar ozone from the four stations of Nepal is compared in different study (Sharma et al., 2011). The TOC estimation by OMI is -1.5 to $+3.9 \%$ for cloud free condition and $-3.5 \%$ to $+4.4 \%$ for cloudy condition

The monthly ozone value in Dobson units (DU) also follows an annual cycle where minimum is observed during December and maximum in April or May. The ozone also fluctuates year to year. There is also increasing trend of the columnar ozone with latitude (not shown here). The long-term monthly average of columnar ozone is also shown in Figure 8. We have also observed a decreasing trend of columnar ozone in all

stations. The monthly average plot shows that the ozone level 255-270 DU is found in January and reaches the highest in April or May at the level of 285-295 DU and decreases a lowest value at 250-260 DU in December. Large variation of the columnar ozone is also observed from January to May. Table 2 shows a monthly mean TOC value and the standard deviation of all the sites from Nepal Himalayas. 

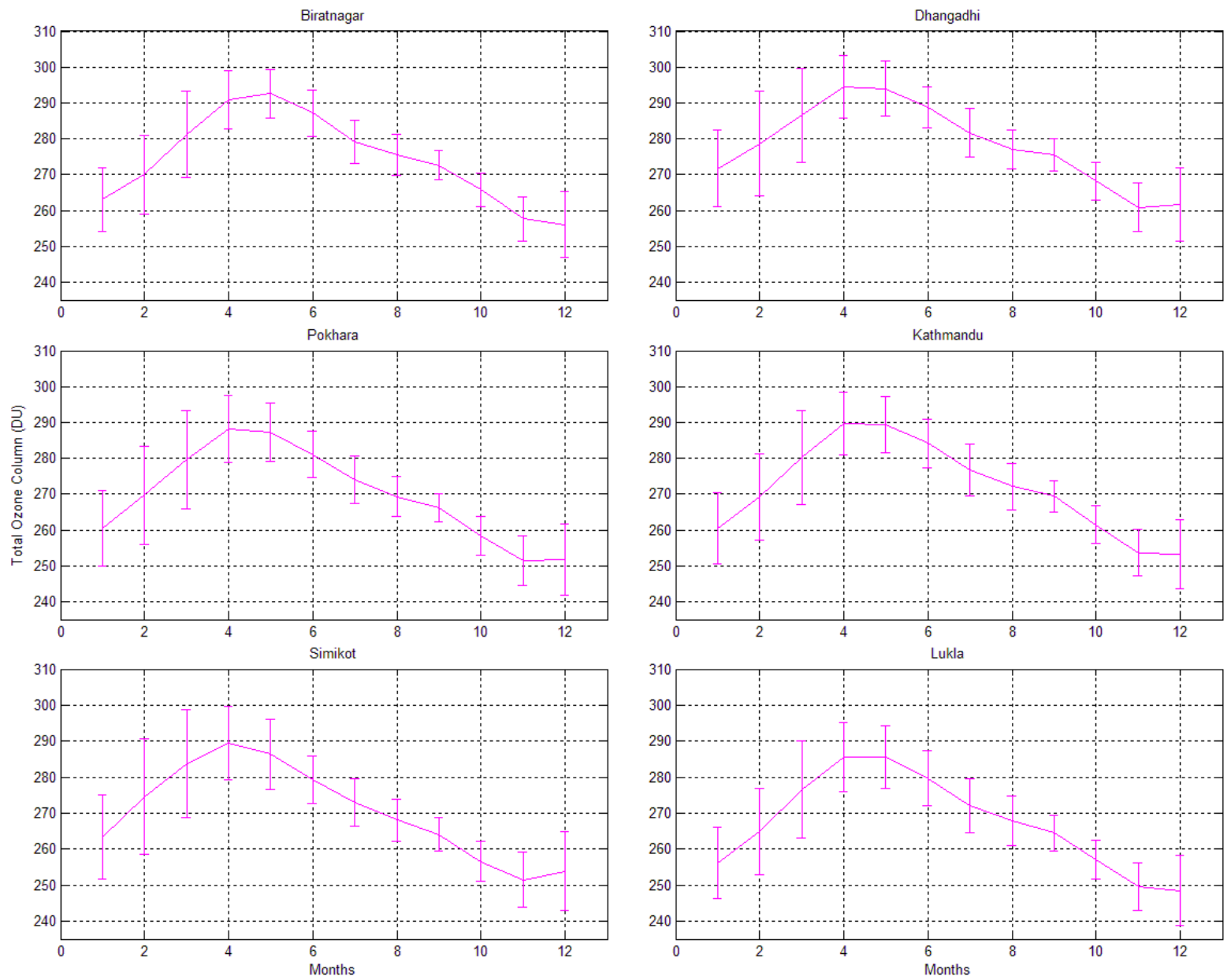

Figure 8: Monthly mean total ozone column climatology for all six sites of Nepal using TOMS/OMI overpass data from November 1978 - March 2012. Error bar shows $\pm 1 \sigma$ of the standard deviation from the mean.

\subsection{Discussion}

Diurnal variability of the four stations shows in the summer season UV index is high to extreme range. The highest altitude station receives more than 16 in a clear sky day around noon when the atmosphere is also clean due to rainfall washout of the aerosols. Altitudinal variation is distinctly visible at the diurnal plots. The rate of increase of UVI is found to vary $7-8 \% / \mathrm{km}$ to $35 \% / \mathrm{km}$. This means at further higher altitude (where we have no station), UVI is still higher than 16. Since, cloud and aerosol or pollution in the atmosphere prevents the UV radiation reaching the ground; we have found similar or even lower UVI in Kathmandu (1350 m) than the lower altitude station Pokhara $(850 \mathrm{~m})$. The lower UV index in the Kathmandu valley as compared to Pokhara valley is due to the high level of pollution level or aerosol content which compensates the altitudinal increase in UV index. Bowl shaped valley with more than 3 million population, heavy traffic, unpaved road condition, old vehicles with comparatively higher level of emission rate, large number of brick factory etc. are responsible for higher level of pollution level or aerosol content 
in Kathmandu valley. The Pokhara valley is relatively cleaner than Kathmandu valley where number of rainy days are also higher than the Kathmandu. When selecting a threshold of the cloud transmission factor for clear sky days, we have found different heights of the oval even in some consecutive days. This is likely due to the difference between the aerosol loading or presence of thin cirrus cloud. Dahlback et al. (2007) have found the in the Lhasa, Tibet that the level of UV index reaches to above 15 on clear days and sometimes exceeds 20 on partially cloudy days. Low altitude station despite the fact that more humid and hot climate receives comparatively less erythemal UV radiation compare to high altitude and cold climate station in a same day. People notion is very poor to understand the level of erythemal UV radiation they receive in such a high altitude region.

UV index climatology for clear sky condition at local noon using OMI station overpass data of six sites of Nepal is also presented in the study. We have taken a simple ratio of satellite and ground to correct the bias as often found in the satellite data. We believed at the beginning that satellite estimation (UVI) is closer enough with the ground measurements at the relatively clean sites of High mountain of Nepal, but actual satellite estimation is more diverse than the lower altitude station. We have also found that reflectivity and cloud optical depth have bimodal distribution in one of high altitude station (Lukla, $2850 \mathrm{~m}$ ). The cloud optical depth is zero even when the reflectivity measurement is 0.8 . This is because satellite assumes clear sky above certain altitude for example $2 \mathrm{~km}$ (Krotkov et al. 2002). The OMI also uses high surface albedo values. When comparing surface albedo with time series data from Nepal, we have found that albedo often exceeds 0.1 in monsoon season where there is no snow at all in the ground. That may be the small patches of low level cloud in the OMI grid.

The UV index climatology follows the annual cycle where minimum close to 3-4 is found for

Table 2: Long-term monthly mean and standard deviation of total ozone column for six locations of Nepal Himalayas using TOMS/OMI monthly average overpass data (1978-2012).

\begin{tabular}{|c|c|c|c|c|c|c|c|c|c|c|c|c|c|}
\hline Location & Para & Jan & Feb & Mar & Apr & May & Jun & Jul & Aug & Sep & Oct & Nov & Dec \\
\hline \multirow{2}{*}{ Birat. } & $\mu$ & 263.1 & 270.0 & 281.2 & 290.9 & 292.6 & 287.2 & 279.2 & 275.5 & 272.6 & 265.8 & 257.6 & 256.1 \\
\hline & $\sigma$ & 8.9 & 10.9 & 12.1 & 8.2 & 6.8 & 6.5 & 6.0 & 5.6 & 4.2 & 4.7 & 6.1 & 9.2 \\
\hline \multirow{2}{*}{ Dhan. } & $\mu$ & 271.6 & 278.6 & 286.5 & 294.5 & 294.0 & 288.8 & 281.6 & 277.0 & 275.4 & 268.2 & 260.8 & 261.7 \\
\hline & $\sigma$ & 10.7 & 14.6 & 13.1 & 8.8 & 7.7 & 5.7 & 6.9 & 5.5 & 4.5 & 5.2 & 6.8 & 10.2 \\
\hline \multirow{2}{*}{ Pokh. } & $\mu$ & 260.5 & 269.7 & 279.6 & 288.1 & 287.2 & 281.1 & 274.1 & 269.3 & 266.3 & 258.3 & 251.4 & 251.7 \\
\hline & $\sigma$ & 10.6 & 13.7 & 13.7 & 9.2 & 8.1 & 6.4 & 6.7 & 5.6 & 3.9 & 5.3 & 6.9 & 10.1 \\
\hline \multirow{2}{*}{ Kath. } & $\mu$ & 260.5 & 269.2 & 280.2 & 289.6 & 289.4 & 284.1 & 276.7 & 272.1 & 269.4 & 261.4 & 253.7 & 253.2 \\
\hline & $\sigma$ & 9.9 & 12.1 & 13.1 & 8.8 & 7.7 & 6.8 & 7.3 & 6.5 & 4.5 & 5.3 & 6.4 & 9.6 \\
\hline \multirow{2}{*}{ Simi. } & $\mu$ & 263.4 & 274.6 & 283.7 & 289.4 & 286.4 & 279.3 & 273.0 & 268.1 & 264.0 & 256.6 & 251.4 & 253.9 \\
\hline & $\sigma$ & 11.6 & 16.1 & 14.9 & 10.2 & 9.7 & 6.6 & 6.6 & 5.9 & 4.6 & 5.6 & 7.7 & 11.0 \\
\hline \multirow{2}{*}{ Lukla } & $\mu$ & 256.1 & 264.7 & 276.6 & 285.6 & 285.5 & 279.6 & 272.0 & 267.8 & 264.5 & 257.0 & 249.5 & 248.5 \\
\hline & $\sigma$ & 9.9 & 12.0 & 13.4 & 9.5 & 8.7 & 7.7 & 7.4 & 6.8 & 4.9 & 5.4 & 6.7 & 9.8 \\
\hline $\begin{array}{l}\text { Total } \\
\text { year }\end{array}$ & $\mathrm{n}$ & 31 & 31 & 30 & 30 & 29 & 27 & 29 & 29 & 30 & 30 & 30 & 30 \\
\hline
\end{tabular}


the winter months and 9-12 is found for the spring (April and May). Ozone climatology of nearly thirty years monthly average data from TOMS/OMI satellite shows that total ozone column also follows the annual cycle where minimum is found in December and maximum is found in April and May as obtained in the other studies (Kalapureddy et al., 2008; Ganguly and Iyer, 2005).

\section{CONCLUSION}

We have performed a climatological study of UV index derived from OMI satellite for local noon at clear sky condition. Before the using the OMI data, we have applied a correction factor using a ratio comparing clear sky UV index data from the ground measurements and satellite estimation. We have also found two discrepancies in the OMI data. The first is the surface albedo is often found more than 0.1 during the monsoon season, which, theoretically, should be less than 0.1 . The reason, as discussed before, is due to the confusion with the patches of low level cloud often found in the OMI grid during the monsoon season. The second is that the OMI algorithm assumes zero cloud optical depth above a certain altitude. In the present OMI algorithm, $2 \mathrm{~km}$ has been taken as a threshold value in which cloud optical depth is zero above that altitude. Since Lukla station is already $2850 \mathrm{~m}$, the discrepancy of ground measured UV index and satellite estimated UV index will be certainly more in those stations with more than $2 \mathrm{~km}$ altitude (e.g. Lukla, 2850 $\mathrm{m})$. Therefore further improvements will be needed in the OMI data.

Looking an oval shape curve of UV index (without sharp kinks) also makes differences in the diurnal variability of UV index. We can receive high UV index when sky is cloud- free and atmosphere is clean. Measurement data from the high altitude station shows that the values goes up to 16 in clear sky monsoon period where atmosphere is also clean. Other low altitude stations also receive a high dose of erythemal UV radiation, demands to use some sort of protection mechanism according to the WMO guidelines.

Ozone climatology using the TOMS/OMI monthly mean from 1978 to 2012 follows the annual cycle, minimum in December and maximum in April/May. Inter annual variability is also significant. We have found a decreasing trend of ozone in all the six sites of Nepal in the 30 years using a simple linear regression.

\section{REFERENCES}

Antón, M., Cachorro, V. E., Vilaplana, J. M., Toledano, C., Krotkov, N. A., Arola, A., Serrano, A., and de la Morena, B, 2010: Comparison of UV irradiances from Aura/Ozone Monitoring Instrument (OMI) with Brewer measurements at El Arenosillo (Spain)-Part 1: Analysis of parameter influence, Atmos. Chem.

Phys., 10, 5979-5989.

Bais, A. F., Tourpali, K., Kazantzidis, A., Akiyoshi, H., Bekki, S., Braesicke, P., Chipperfield, M. P., Dameris, M., Eyring, V., Garny, H., Iachetti, D., Jöckel, P., Kubin, A., Langematz, U., Mancini, E., Michou, M., Morgenstern, O., Nakamura, T., Newman, P. A., Pitari, G., Plummer, D. A., Rozanov, E., Shepherd, T. G., Shibata, K., Tian, W., and Yamashita, Y, 2011: Projections of UV radiation changes in the 21st century: impact of ozone recovery and cloud effects, Atmos. Chem. Phys., 11, 7533-7545. 
Dahlback, A, 1996: Measurements of biologically effective UV doses, total ozone abundances, and cloud effects with multichannel, moderate bandwidth filter instruments, Applied Optics 35, (33).

Dahlback, A., Gelsor, N., Stamnes, J. J. and Gjessing, Y, 2007: UV measurements in the $3000-5000 \mathrm{~m}$ altitude region in Tibet, J. Geophys. Res., 112, D09308.

Eck, T.F., Bhartia, P.K., and Kerr, J.B, 1995: Satellite estimation of spectral UVB irradiance using TOMS derived total ozone and UV reflectivity, Geophys. Res. Lett., 22(5), 611-614.

Ganguly, N.D., Iyer, K.N, 2005: Study of variation in columnar ozone concentration at Rajkot, Journal of Indian Geophys. Union 9 (3).

Grobner, J.: Report in Protocol of the Intercomparision at the University of Oslo, Norway on May 30 to June 04, 2010 with the travelling reference spectroradiometer qasume from PMOD/ WRC, 2010, available in http://www. pmodwrc.ch/euvc/qasume_audit/ reports/2010_06 norway oslo.pdf.

Høiskar, B. A. K., Haugen, R., Danielsen, T., Kylling, A., Edvardsen, K., Dahlback, A., Johnson, B., Blumthaler, M. and Schreder, J, 2003: Multichannel moderate-bandwidth filter instrument for measurementoftheozone-columnamount, cloud transmittance, and ultraviolet dose rates, Applied Optics . 42 (18), 3472-3479.

Kalapurreddy, M.C.R, Ernest Raj, P., and Devera, S, 2008: Total ozone variation over oceanic region around Indian subcontinent during pre-monsoon of 2006, Atmos. Chem. discuss., 8, 3143-3162.
Kalliskota, S., Kaurola, J., Taalas, P., Herman, J.R., Celarier, E.A., and Krotkov, N.A, 2000: Comparison of daily UV doses estimated from Nimbus 7/TOMS measurements and ground-based spectroradiometric data, J. Geophys. Res. 105(D4), 5059-5067.

Kazadzis, S., Bais, A., Balis, D., Kouremeti, N., Zempila, M., Arola, A., Giannakaki, E., Amiridis, V., and Kazantzidis, A, 2009: Spatial and temporal UV irradiance and aerosol variability within the area of an OMI satellite pixel, Atmos. Chem. Phys. 9, 4593-4601.

Krotkov, N. A., Herman, J. R., Bhartia, P.K., Fioletov, V., and Ahmad, Z, 2001: Satellite estimation of spectral surface UV irradiance 2. Effects of homogeneous clouds and snow, J.Geophys. Res. 106, 11,743-11,759.

Krotkov, N.A., Herman, J., Bhartia, P.K., Colin Seftor, Arola, A., Kaurola, J., Taalas, P., Vasilkov, P.: OMI Surface UV Irradiance Algorithm, Editors: P. Stammes and R. Noordhoek, TBD-OMI-03, Version 2, August 2002.

Levelt, P.F., Veefkind, J.P., Voors, R.H.M. and Vries, J. de: OMI Algorithm Theoretical Basis Document Volume I OMI Instrument, Level 0-1b processor, Calibration \& Operations, 2002.

Pfeifer, M. T., Koepke, P. and Reuder, J, 2006: Effects of altitude and aerosol on UV radiation, J. Geophys. Res. 111, D01203.

Sharma R.K., B.K. Bhattarai, B. Sapkota, M.N. Gewali and B. Kjeldstad 2011: Variation of black carbon aerosol on six continuous strikes days of Kathmandu valley: a case study, Journal of the Institute of Engineering 8, (3) 105-113. 2011 
Tanskanen, A., et al, 2007: Validation of daily erythemal doses from Ozone Monitoring Instrument with ground-based UV measurement data, J. Geophys. Res. 112, D24S44.

Watanabe, S., K. Sudo, T. Nagashima, T. Takemura, H. Kawase, and T. Nozawa, 2011 Future projections of surface UV-B in a changing climate, J. Geophys. Res. 116, D16118.
WHO: Global Solar UVI, a practical guide, a joint recommendation of World Health Organization, World Meteorological Organization, United nations Environment Programme and International Commission on NonIonizing Radiation Protection, WHO/ SDE/OEH/02.2. 2002

WMO: Stratospheric Ozone and Surface Ultraviolet Radiation, Scientific Assessment of Ozone Depletion: 2010, World Meteorological Organization Global Ozone Research and Monitoring Project-Report No. 52. 2010. 